\title{
The importance of food presentation for animal welfare and conservation
}

\author{
BY ROBERT J. YOUNG
}

\author{
Animal Department, Edinburgh Zoo, Murrayfield, Edinburgh EH12 6TS
}

The feeding of all captive animals is more complex than offering a diet with the correct balance of nutrients; the diet should be offered in a manner that is appropriate for the reasons why that animal is kept in captivity.

The roles of the modern zoo are to conserve species from extinction, to educate people about conservation, to provide a place of scientific research and to provide a place of public entertainment (Tudge, 1991). Underpinning these four roles is the welfare of the animals. Thus, an appropriate feeding programme for zoo-housed animals must consider the diet in terms of nutrients and how the diet is presented to the animals in terms of the four objectives of modern zoos and animal welfare.

\section{TYPE OF FOOD OFFERED TO CARNIVORES}

Within many of the world's zoological collections three types of food are commonly offered to obligate carnivores such as felids; these are, whole carcasses, prepared (muscle) meat and complete (soft textured) diets. Each of these types of foods offered can create problems with physical health, animal welfare, re-introduction or animal husbandry.

\section{Carcass feeding}

The feeding of whole carcasses often requires mineral supplementation to ensure that the animal is receiving all the necessary nutrients (Allen et al. 1996). A problem with wholecarcass feeding is that if the animal is offered a large whole carcass it may selectively eat only part of the carcass, for example, the muscle material and liver (Allen et al. 1996). This may result in the animal not receiving an adequate diet. Care is needed, therefore, when offering whole carcasses, to ensure that the animal consumes all the offered food. A second problem with feeding whole carcasses is their availability. Many zoos, especially in North America, have difficulty finding an adequate and constant supply of whole carcasses (Allen et al. 1996). Feeding whole carcasses (especially of domestic livestock deemed unfit for human consumption) also brings with it the risk of fatal food poisoning (see Nichols, 1989) and serious disease (e.g. spongiform encephalopathy; for review, see Kirkwood \& Cunningham, 1994).

In many Western societies, the zoo-going public object to seeing large carnivores feeding on whole carcasses (see Ings et al. 1997b). In some instances, this has resulted in some zoos completely stopping the feeding of whole carcasses to carnivores, since zoos are dependent on the zoo-going public for their financial survival. Finally, the feeding of whole carcasses can be unpopular with zoo staff as pens often require more cleaning after feeding whole carcasses than after prepared meat or complete diets.

\section{Feeding prepared meat}

A popular alternative to feeding whole carcasses is the feeding of prepared meat, often skinned muscle meat from domestic livestock. Research has shown that such a diet is often 
nutritionally inadequate (U1lrey \& Bernard, 1989) and, therefore, requires nutrient supplementation (Allen et al. 1996). The feeding of prepared meat carries with it the same risks of food poisoning and disease as whole-carcass feeding. The feeding of this type of diet is costly and, therefore, is only feasible in wealthier zoos in the USA (Allen et al. 1996).

A major problem of feeding this type of diet is the reduced sensory input derived by the animal (Bond \& Lindburg, 1990). For example, felids have a highly-developed sensory system that enables them to process carcasses; this system consists of vision, olfaction, and tactile inputs from their whiskers. When feeding on a carcass a felid is unable to focus its eyes on the food and, therefore, uses its sense of smell to aid food identification. In the wild, after killing prey, felids lean over their prey forming their whiskers into a forward projecting net and with their whiskers they feel the direction of the fur or feathers on their prey (Stein et al. 1976; Leyhausen, 1979). This is important as felids have a set method of dissecting prey items. A margay (Felis wiedi), for example, will start consuming prey by first biting off the head and then sucking out the prey's intestines. Along with the use of the whiskers felids also possess an abundance of mechano-receptors linked to the canines, which suggests that these killing teeth can 'feel' their way to the cervical vertebrae to perform the killing bite (Ewer, 1973; Kitchener, 1991).

Young felids learn what is appropriate prey by observing the carcasses that their mother brings back from her hunting trips (for review, see Kitchener, 1997). If captive carnivores are to be successfully re-introduced it is important that they are given the experience of learning to identify appropriate prey species. In an experimental reintroduction of cheetahs (Acinonyx jubatus) that had only experience of killing Barbary sheep (Ammotragus lervia), the cheetahs started to hunt giraffe (Giraffa camelopardalis) calves and on occasions attempted to kill African buffalo (Syncerus caffer), zebra (Equus burchelli) and wildebeest (Connochaetes taurinus; Pettifer, 1981). This was despite an abundance of their natural prey, impala (Aepyceros melampus). Not only is attacking inappropriate prey energetically costly but it is also dangerous (Kitchener, 1997). It is obviously impractical to offer zoo-housed carnivores the carcasses of prey species that would be appropriate in the wild. It may be possible, however, to offer appropriate prey items to kittens who are eventually destined for re-introduction, during their sensitive period (see Caro, 1980a,b) when they learn to recognize prey. It should be acknowledged, however, that this exposure to appropriate prey is not essential for successful reintroduction, but will greatly improve the likelihood of success.

\section{Feeding soft textured diets}

In many Western zoos, the feeding of complete soft textured diets is becoming popular, because they are cheap, safe, nutritionally-complete, publicly-acceptable and zoo staff like them because of the reduction in cleaning. However, such diets are not a panacea for the feeding of obligate carnivores. The main physical health problem resulting from such diets is poor oral health. Fitch \& Fagan (1982), in their survey, reported that $70 \%$ of captive cheetahs fed on soft textured diets had developed focal palatine erosion. They found that this condition was caused by maloccluded dentition, resulting in tooth tips making contact with the soft palate each time the mouth was closed. They concluded that 'lack of vigorous tearing and chewing exercise' was the main causal factor. Research by Corruccini \& Beecher (1982) on squirrel monkeys (Saimiri sciureus) fed only on soft diets found similar occular disorders. Such oral health problems can be overcome by cleaning the animal's 
teeth; however, to do this requires the animal to be anaesthetized and this carries with it a risk.

Furthermore, there is evidence that feeding felids soft textured diets weakens the structure of the muscles operating the jaw (Kitchener, 1991; Duckler \& Binder, 1997). Hollister (1917) examined the skulls of 100 East African lions (Panthera leo); he found that captive lion skulls showed signs of atrophy probably resulting from 'disuse of muscles involved in normal killing and consumption of prey'. This has obvious implications for the re-introduction of captive carnivores. Fitch \& Fagan (1982) noted that captive cheetah would not chew bones unless there was meat attached to them. Offering of bones or dog chews, therefore, is unlikely to alleviate such problems for certain species of zoo-housed carnivores.

As with prepared meat, such diets create limited sensory input for the animals consuming them and the animals learn nothing about prey identification. There is also evidence that such diets result in reduced feeding motivation (Bond \& Lindburg, 1990), implying that such diets are not as palatable as whole carcasses.

\section{EFFECT OF FOOD COMPOSITION ON BEHAVIOUR}

The nutrients contained within an animal's diet can have a significant effect on the animal's behaviour and welfare. For example, experiments have shown that either mineralor protein-deficient diets can result in growing pigs mutilating the bodies of other individuals by biting off their tails (Fraser, 1987; Fraser et al. 1991). Research has shown that horses fed on diets containing inadequate levels of roughage often develop abnormal behaviour (Fraser \& Broom, 1990; McGreevy et al. 1995). Specifically, such animals develop oral stereotypies, the presence of which are thought to indicate that the performer is experiencing suboptimal animal welfare (Mason, 1991). Other studies have shown that growing pigs fed on inadequate protein levels will spend more time directing foraging behaviour at straw than individuals who are able to meet their protein requirements (Jensen et al. 1993). The effects of undernutrition on the behaviour and welfare of domestic livestock are well documented (for review, see Lawrence et al. 1993); however, little is known about such effects on zoo-housed animals.

\section{FEEDING REGIMEN: PANTHERA}

Members of the Panthera genus of felids ('big cats') are not considered food-restricted in zoos but are usually not fed every day (i.e. 'starve days' are used; Allen et al. 1996). Panthera are often fed at fixed times and at fixed time intervals; for example, at Edinburgh Zoo these species are fed in the morning once every $3 \mathrm{~d}$ (Lyons et al. 1997). They are most often fed on prepared meat, which is usually offered individually to avoid fighting at feeding time. Live vertebrate prey is never fed within the UK because it is illegal to do so (Animal Protection Act (1911, 1912); UK Government, 1912) and in countries where it is not illegal, it is not done, because of ethical reasons and public sensitivity (Synder, 1977).

Research by Lyons et al. (1997) found that Panthera fed every $3 \mathrm{~d}$ performed more stereotypic pacing on days when they were not fed. Such pacing is not desirable from a welfare point of view and results in many complaints from zoo visitors concerned about the welfare of the animals. In a subsequent experiment, Lyons \& Young (1997) altered the feeding regimen of their subjects to daily feeding. The consequence of this was an overall reduction in the level of stereotypic pacing; however, most of the reduction occurred before feeding, with post-feeding levels of pacing remaining unaffected. These results suggest that 
the link between feeding of Panthera and the performance of abnormal behaviour is a multi-factorial one. The reduction in prefeeding pacing can be explained by the animals no longer anticipating being fed (Anderson \& Shettleworth, 1977). However, the lack of effect on post-feeding pacing suggests either that the food was inadequate in a sensory way or that the method of food presentation was inadequate. For example, post-feeding stereotypies in broiler breeders are thought to be caused by the frustration of consummatory behaviour when meals are finished rapidly (Savory et al. 1992).

\section{Frequency of feeding}

Traditionally, most zoo-housed birds and mammals have been fed once or twice daily. Often animals were fed just before the zoo closed, in their indoor quarters; this method of feeding was used to encourage animals to move inside so that they could be locked-up for the night.

Few animals, other than large carnivores such as members of the genus Panthera, naturally consume just one large meal daily. Members of the genus Felidae generally consume many small meals each day; for example, the domestic cat will consume between twelve and twenty meals daily when free feeding under conditions of ad libitum food availability (Rainbird, 1988). It has been found that the practice of feeding domestic cats two to three large meals daily, as is typical for pet cats, can result in an alkaline tide in the blood that may lead to the development of urolithiasis (bladder stones). I have been unable to locate any literature on the incidence of this condition in small exotic felids; however, it is likely that this condition could also occur in these felids.

The other effect of reducing the number of meals offered daily to an animal is the possibility of shifting its method of short-term food-intake regulation mechanism. De Castro (1988) has shown that when rats are fed only five meals daily their short-term foodintake regulation mechanism switches from being postprandially regulated (i.e. hunger mechanism controlled) to preprandially regulated (i.e. satiety mechanism controlled). Thus, animals receiving a restricted frequency of meals fill their stomachs to an upper limiting threshold, rather than feeding when their stomachs have emptied to a minimum threshold. The physical health and welfare consequences of this have not been investigated.

\section{ENVIRONMENTAL ENRICHMENT}

Enriching the way zoo-housed animals are fed is now a widely employed method of improving the welfare of these animals (for example, see Shepherdson et al. 1993; Williams et al. 1996; Ings et al. 1997a). The other potential benefits of feeding enrichment are as training for re-introduction and the creation of a more informative exhibit for zoo visitors (Shepherdson, 1994).

Feeding enrichment can be as simple as scattering the food of primates around their enclosure, or as sophisticated as using artificial mechanical prey which carnivores must capture to receive a food reward (Synder, 1977; Markowitz \& Laforse, 1987). The scattering of food for primates encourages a time budget closer to that displayed by a species wild counterpart, and often reduces or eliminates the performance of abnormal behaviour that is thought to be indicative of reduced welfare status (Mason, 1991). This is widely perceived as an improvement in animal welfare (but see pp. 1099-1101); certainly it is more educational for the zoo visitor. Whether or not the behaviour of the wild animal is a good model for improving animal welfare is open to debate (see Veasey et al. $1996 a, b)$. However, the scatter-feeding of foraging animals housed in groups often ensures 
that all individuals within the group have access to all types of food items (Chamove $e t$ al. 1982; Boccia et al. 1984). Feeding of group-housed animals in a single place could result in dominant individuals selecting an unbalanced diet from the food items available (S. D. Crissey, personal communication). Furthermore, the offering of food in a localized manner produces a food source that can be defended (see Davies \& Houston, 1984); this often results in aggression (Schnebel \& Griswold, 1983). Studies have shown that aggression at feeding time can be reduced by randomizing feeding times, using multiple feeding stations or scatter-feeding (Chamove et al. 1982; Bloomsmith et al. 1988; Bloomsmith, 1989; Bloomsmith \& Lambeth, 1995).

Feeding enrichment can reduce the occurrence of abnormal behaviour (Shepherdson $e t$ al. 1993) and improve the physical condition of animals (Markowitz et al. 1978). Chamove (1986) found that captive animals often have a much lower muscle:body fat value than their wild counterparts. Thus, making animals obtain their food in an active manner can counteract this problem, and help alleviate problems of obesity. Furthermore, studies on the effects of exercise in human subjects show considerable physiological and psychological benefits; some of which may be accrued by animals experiencing hunting or foraging enrichment (Chamove, 1986).

An interesting finding of some hunting enrichment studies (Shepherdson et al. 1993; Williams et al. 1996; Ings et al. 1997a) is that once animals have experience of hunting, they appear to become behaviourally activated. For example, Williams et al. (1996) reported that cheetahs given experience of hunting enrichment tripled the hourly frequency of hunting episodes even when the hunting enrichment was not being employed. Williams et al. (1996) also reported that a cheetah took 2 weeks to learn how to use the huntingenrichment device. It has not yet been established whether such techniques increase the success of the re-introduction of carnivores, since the successful re-introduction of carnivores has involved the use of live prey (for example, see Rodriguez et al. 1995). However, as the use of live vertebrate prey is illegal in the UK, this raises serious ethical questions and may be publicly unacceptable (see Ings et al. 1997b).

\section{Public attitude to the idea of feeding live prey to carnivores}

Ings et al. (1997b) have published the only study to-date on the UK public's attitude towards the idea of feeding live prey to carnivores. In general, the public were not found to be as squeamish about this idea as is commonly thought by zoo professionals; especially, if the feeding of live prey occurred in an area off-exhibit to the public. It would be interesting to repeat this study in countries such as the USA, where many zoos state that they feed prepared diets to carnivores because the public complain if they see animals feeding on carcasses. It is obviously unwise for zoos to allow the public to dictate to them what animals should be fed. However, these results give some hope for the practice of feeding live vertebrate prey to carnivores destined for re-introduction.

\section{Effects of increasing feeding time}

One of the most commonly employed forms of environmental enrichment by zoos is to increase feeding time by making animals forage for their food. This is most commonly done by hiding the animal's food, chopping it up into small pieces and scattering it around its enclosure, or making the animal work for the food by extracting it from a puzzle feeder (Chamove et al. 1982; Brent \& Eichberg, 1991; Forthman et al. 1992). In many enrichment studies, an increase in the time spent foraging by animals is equated with an increase in 
their welfare status (for example, see Hayes, 1990; Shepherdson et al. 1993). Such an assumption may be incorrect, however, and only psychological well-being may be increased while there is a detrimental effect on physical well-being.

Much feeding enrichment works on the principle of offering animals a more-thanadequate supply of nutrients, but it 'enriches' the animals, essentially, by decreasing feeding rate, i.e. increasing foraging time. In energetic terms this means that the net rate of energy gain by an animal enriched in this way is reduced. Lemon (1991) found that the life span of zebra finches (Taeniopygia guttata) was positively correlated with maximum feeding rate. Thus, zoos, by employing feeding enrichment, may be reducing the longevity of their animals.

Lemon \& Barth (1992) investigated the relationship between reproductive success in zebra finches and the net rates of energy gain. In their experiment, they used the following four treatments: food (mixed grass seeds) offered undiluted (A) or food diluted with an inedible substance (empty seed hulls or chaff) at $1: 1(\mathrm{w} / \mathrm{w} ; \mathrm{B}), 1: 2(\mathrm{w} / \mathrm{w} ; \mathrm{C})$ or $1: 3$ $(w / w ; D)$. Each experimental treatment had fifteen pairs of birds, all offered the same absolute amount of food daily $(6.7 \mathrm{~g} / \mathrm{bird})$ and the amount of food offered exceeded their metabolic requirements. Furthermore, treatments B-D were designed so that the birds could acquire all their daily nutrient requirements within a $24 \mathrm{~h}$ period. They found that feeding time (min) significantly increased with the level of food dilution (A 32.8, B 48.1, C $60 \cdot 3$, D 106.8) but mean daily food intake did not differ between groups. Thus, their results were not due to differential food intake between treatments. The birds were maintained on these treatments for 45 months and their reproductive success measured. At the end of 45 months all the females in treatment groups B, C and D had died, while $60 \%$ of those on treatment $\mathrm{A}$ were still alive. Mean brood size generally, but not significantly, increased as feeding rate increased. Inter-brood interval only differed significantly between treatment group $D$ and the other three treatment groups $(128.2 v .61 .3 \mathrm{~d}$, for treatment group D and the mean of treatment groups $\mathrm{A}, \mathrm{B}$ and $\mathrm{C}$ respectively). This result was not an effect of increased fledging age, as this did not differ significantly between treatment groups. Furthermore, it was found that treatment $D$ birds produced fledglings with a significantly lower mass when compared with all other treatments $(8.6 v .9 .6 \mathrm{~g}$, for treatment group $\mathrm{D}$ and the mean of treatment groups $\mathrm{A}, \mathrm{B}$ and $\mathrm{C}$ respectively), which did not significantly differ from one another. These results are interpreted as birds on the diluted treatments, especially treatment $\mathrm{D}$, having less time and energy to spend on maintenance and reproduction.

In many feeding enrichment studies the amount of time an individual spends foraging is significantly increased compared with that of the animal being offered its food from a bowl. Gould \& Bres (1986) increased gorilla (Gorilla gorilla) feeding time by $16 \%$ by using browse as a form of foraging enrichment. Thus, zoos using foraging enrichment could potentially be reducing the longevity and reproductive success of animals in their care. However, in the Gould \& Bres (1986) study, abnormal regurgitation and reingestion was significantly reduced. Clearly, as most species housed within zoos are there for captive breeding, this creates a conflict between the goals of the zoo for conservation and concern for animal welfare. However, it is important to remember that animals have evolved foraging time budgets through the process of natural selection, in response to food availability and the nutritional qualities of the food. It is unlikely that any potential adverse effects of feeding enrichment on longevity and reproduction can ever be properly quantified within zoos. Since husbandry, veterinary care and a multitude of other factors progress at such a rapid rate, a comparison between time budgets before feeding enrichment was implemented and after implementation would be meaningless. 
Animal behaviour is flexible and animals in the wild can adjust their time budget in accordance with the trophic quality of their environment and other factors (Leger et al. 1983). This fact has been used by zoos to increase the foraging time of their animals. Young \& Lawrence (1996), using a foraging device ('The Edinburgh Foodball'), were able to demonstrate that it is possible to control how long a domestic sow will forage. In their experiment, they made sows forage for nearly two-thirds of their day, which is longer than the $50 \%$ reported for sows released into a natural environment (Stolba \& Wood-Gush, 1984). It is also in stark contrast to the $10-20 \mathrm{~min}$ that pigs take to consume their food when trough-fed. Given that we have this power to manipulate animals' time budgets, the question arises: 'For how long shall we make animals forage as a form of enrichment?'

Although the arguments presented here are largely inferential and based on the study of only one species (zebra finches), they suggest that zoos should not push the foraging time of their captive animals beyond those reported for their wild counterparts if they wish to achieve comparable reproductive success. If, as happens with a highly-endangered species, the objective of a zoo is to increase reproductive output beyond that of wild counterparts, then foraging time less than that of wild counterparts may be beneficial towards this aim. A final point is that this effect is most likely to be pronounced in small animals with high metabolic rates, such as zebra finches.

\section{Working for food}

In many enrichment studies it is reported (for example, see Shepherdson et al. 1993) that animals prefer to work for food in the presence of identical free food available ad libitum; a phenomenon referred to in the psychological literature as contrafreeloading. However, a review of this literature by Osborne (1977) concluded that none of the studies proved that animals prefer to work for food. Inglis et al. (1997) suggest this phenomenon is principally caused by secondary sources of reinforcement. Most published feeding enrichment studies do not meet the criterion necessary to be considered a true test of the proposition that animals prefer to work for food. Furthermore, such studies rarely use secondary sources of reinforcement associated with food acquisition. These points have been missed by scientists conducting environmental enrichment studies. Thus, one could question the philosophy behind increasing foraging time or making animals work for food as being good for their psychological well-being. However, it is known that animals do not necessarily choose what is good for them in the long term (Dawkins, 1990).

\section{CONCLUSION}

Clearly the feeding of zoo-housed animals is a complex issue. I have covered some of the major problem areas, especially with reference to carnivores. However, there are a number of other important areas, for which space does not permit consideration. For example, should seasonal changes in food abundance be replicated (see Allen et al. 1996), should the genetic basis of food preferences be considered (see Arnold, 1981) or maternal influences on diet choice (see Galef, 1976), or should thermoneutral diets be offered?

Finally, it has been found that certain types of food can have some surprising effects on the behavioural development of animals. For example, Masataka (1993) found that snake fear in captive squirrel monkeys can be activated by feeding them on live insects. The mechanism through which this operates is not understood. However, the implications for the re-introduction of species is obvious. This example illustrates that food can have a multitude of effects on the behaviour of animals. 
In conclusion, if zoos are to be successful in their four stated goals and in their concern for animal welfare, they must give serious consideration to the interface between diet and behavioural processes.

Many of the ideas in this paper have been stimulated principally by discussions with Graham Law and many of Edinburgh's Zoo Keepers too numerous to mention personally. I am grateful to Chris Seal for suggesting my impromptu talk at a nutrition conference be converted into this paper and to Andrew Kitchener for providing me with a copy of his 'in press' paper.

\section{REFERENCES}

Allen, M. E., Oftedal, O. T. \& Baer, D. J. (1996). The feeding and nutrition of carnivores. In Wild Mammals in Captivity, pp. 139-147 [D. G. Kleiman, M. E. Allen, K. V. Thompson, S. Lumpkin and H. Harris, editors]. Chicago: The University of Chicago Press.

Anderson, M. C. \& Shettleworth, S. J. (1977). Behavioural adaptation to fixed interval and fixed time food delivery in golden hamsters. Journal of Experimental Animal Behaviour 25, 33-49.

Arnold, S. J. (1981). Behavioral variation in natural populations II. The inheritance of a feeding response in crosses between geographic races of the garter snake, Thamnophis sirtalis. Evolution 35, 510-515.

Bloomsmith, M. A. (1989). Feeding enrichment for great apes. In Housing, Care and Psychological Well Being of Captive and Laboratory Primates, pp. 336-356 [E. F. Segal, editor]. Park Ridge, NJ: Noyes Publications.

Bloomsmith, M. A., Alford, P. L. \& Maple, T. L. (1988). Successful feeding enrichment for captive chimpanzees. American Journal of Primatology 16, 155-164.

Bloomsmith, M. A. \& Lambeth, S. P. (1995). Effects of predictable versus unpredictable feeding schedules on chimpanzee behaviour. Applied Animal Behaviour Science 44, 65-74.

Boccia, M. L., Laudenslager, M. \& Reite, M. (1984). Spatial distribution of food and dominance related behaviors in bonnet macaques: A laboratory study. American Journal of Primatology 6, 399.

Bond, J. C. \& Lindburg, D. (1990). Carcass feeding of captive cheetahs (Acinonyx jubatus): the effects of naturalistic feeding program on oral health and psychological well being. Applied Animal Behaviour Science 26, 373-382.

Brent, L. \& Eichberg, J. W. (1991). Primate puzzleboard: A simple environmental enrichment device for captive chimpanzees. Zoo Biology 10, 353-360.

Caro, T. M. (1980a). The effects of experience on the predatory patterns of cats. Behavioral and Neural Biology $29,1-28$.

Caro, T. M. (1980b). Effects of mother, object play and adult experience on predation in cats. Behavioral and Neural Biology 29, 29-51.

Chamove, A. S. (1986). Exercise improves behaviour: A rationale for occupational therapy. British Journal of Occupational Therapy 49, 83-86.

Chamove, A. S., Anderson, J. R., Morgan-Jones, S. C. \& Jones, S. P. (1982). Hygiene, feeding and behavioural enhancement in eight primate species. International Journal for the Study of Animal Problems 3, 308-318.

Corruccini, R. S. \& Beecher, R. M. (1982). Occlusal variation related to soft diet in a nonhuman primate. Science 218, 74-76.

Davies, N. B. \& Houston, A. I. (1984). Territory economics. In Behavioural Ecology, an Evolutionary Approach, pp. 148-169 [J. R. Krebs and N. B. Davies, editors]. Oxford: Blackwell Scientific Publications.

Dawkins, M. S. (1990). From an animal's point of view: motivation, fitness, and animal welfare. Behavioral and Brain Sciences 13, 1-61.

De Castro, J. M. (1988). The meal pattern of rats shifts from postprandial regulation to preprandial regulation when only five meals per day are scheduled. Physiology and Behavior 43, 739-746.

Duckler, G. L. \& Binder, W. J. (1997). Previously undescribed features in the temporalis and masseteric musculature of several large felids raised in captivity. Zoo Biology 16, 187-191.

Ewer, R. F. (1973). The Carnivores. New York: Cornell University Press.

Fitch, H. M. \& Fagan, D. A. (1982). Focal palatine erosion associated with dental malocclusion in captive cheetahs. Zoo Biology 4, 295-310.

Forthman, D. L., Elder, S. D., Bakeman, R., Kurkowski, T. W., Noble, C. C. \& Winslow, S. W. (1992). Effects of feeding enrichment on behavior of 3 species of captive bears. Zoo Biology 11, 187-195.

Fraser, D. (1987). Mineral deficient diets and the pig's attraction to blood: implications for tail-biting. Applied Animal Behaviour Science 17, 61-68.

Fraser, D., Bernon, D. E. \& Ball, R. O. (1991). Enhanced attraction to blood by pigs with inadequate dietary supplementation. Canadian Journal of Animal Science 67, 909-918. 
Fraser, A. F. \& Broom, D. M. (1990). Farm Animal Behaviour and Welfare. London: Bailliere Tindell.

Galef, B. G. (1976). The social transmission of acquired behavior: a discussion of tradition and social learning in vertebrates. Advances in the Study of Behavior 6, 77-100.

Gould, E. \& Bres, M. (1986). Regurgitation and reingestion in captive gorillas: description and intervention. Zoo Biology 5, 241-250.

Hayes, S. L. (1990). Increasing foraging opportunities for a group of captive capuchin monkeys (Cebus capucinus). Laboratory Animal Science 40, 515-519.

Hollister, N. (1917). Some effects of environment and habit on captive lions. Proceedings of US National Museum 53, 177-193.

Inglis, I. R., Forkman, B. \& Lazarus, J. (1997). Free food or earned food? A review and fuzzy model of contrafreeloading. Animal Behaviour 53, 1171-1191.

Ings, R., Waran, N. K. \& Young, R. J. (1997a). Effect of wood-pile feeders on the behaviour of captive bush dogs, Speothos venaticus. Animal Welfare 6, 145-152.

Ings, R., Waran, N. K. \& Young, R. J. (1997b). Attitude of zoo visitors to the idea of feeding live prey to zoo animals. Zoo Biology (In the Press).

Jensen, M. B., Kyriazakis, I. I. \& Lawrence, A. B. (1993). The activity and straw directed behaviour of pigs offered foods of different protein content. Applied Animal Behaviour Science 37, 211-221.

Kirkwood, J. K. \& Cunningham, A. A. (1994). Epidemiological aspects of spongiform encephalopathy in captive wild animals in the British Isles. Veterinary Record 135, 296-303.

Kitchener, A. C. (1991). The Natural History of the Wild Cats. London: Christopher Helm.

Kitchener, A. C. (1997). Watch with mother: A review of social learning in the felidae. Proceedings of the Mammal Society (In the Press).

Lawrence, A. B., Terlouw, E. M. C. \& Kyriazakis, I. I. (1993). The behavioural effects of undernutrition in confined farm animals. Proceedings of the Nutrition Society 52, 219-229.

Leger, D. W., Owings, D. H. \& Cross, R. G. (1983). Behavioral ecology of time allocation in California ground squirrels (Spermophilius beecheyi): microhabitat effects. Joumal of Comparative Psychology 97, $283-291$.

Lemon, W. C. (1991). Fitness consequences of foraging behaviour in the zebra finch. Nature 352, $153-155$.

Lemon, W. C. \& Barth, R. H. (1992). The effects of feeding rate on reproductive success in the zebra finch, Taeniopygia guttata. Animal Behaviour 44, 851-857.

Leyhausen, P. (1979). Cat Behaviour. New York: Garland STMP Press.

Lyons, J. \& Young, R. J. (1997). Effects of feeding regime manipulation upon the behaviour of felids at Edinburgh Zoo. The Royal Zoological Society of Scotland Annual Report 1996, pp. 61-65. Edinburgh: Featherhall Press.

Lyons, J., Young, R. J. \& Deag, J. M. (1997). The effects of physical characteristics of the environment and feeding regime on the behavior of captive felids. Zoo Biology 16, 71-83.

McGreevy, P. D., Cripps, P. J., French, N. P., Green, L. E. \& Nicol, C. J. (1995). Management factors associated with stereotypic and redirected behaviour in the Thoroughbred horse. Equine Veterinary Journal $27,86-91$.

Markowitz, H. \& Laforse, S. (1987). Artificial prey as behavioural enrichment devices for felines. Applied Animal Behavioural Science 18, 31-43.

Markowitz, H., Schmidt, M. J. \& Moody, A. (1978). Behavioral engineering and animal health in the zoo. International Zoo Year Book 18, 190-195.

Masataka, N. (1993). Effects of experience with live insects on the development of fear of snakes in squirrel monkeys, Saimiri sciureus. Animal Behaviour 46, 741-746.

Mason, G. J. (1991). Stereotypy: a critical review. Animal Behaviour 41, 1015-1037.

Nichols, D. K. (1989). Food-borne bacterial disease caused by uncooked horsemeat products. In Proceedings of the Sixth and Seventh Annual Dr Scholl Conference on the Nutrition of Captive Wild Animals, pp. 5-10 [T. P. Mechan and M. E. Allen, editors]. Chicago: Lincoln Park Zoological Society.

Osborne, S. R. (1977). The free food (contrafreeloading) phenomenon: a review and analysis. Animal Learning and Behaviour 5, 221-235.

Pettifer, H. L. (1981). The experimental release of captive-bred cheetah (Acinonyx jubatus) into the natural environment. In Worldwide Furbearer Conference Proceedings, pp. 1001-1024 [J. A. Chapman and D. Pursley, editors]. Vancouver: R. R. Donnelly.

Rainbird, A. L. (1988). Feeding throughout life. In The Waltham Book of Cat and Dog Nutrition, 2nd ed., pp. 75-96 [A. T. B. Edney, editor]. Oxford: Pergamon Press Ltd.

Rodriguez, A., Barrios, L. \& Delibes, M. (1995). Experimental release of an Iberian lynx (Lynx pardinus). Biodiversity and Conservation 4, 382-394.

Savory, C. J., Seawright, E. \& Watson, A. (1992). Stereotyped behaviour in broiler breeders in relation to husbandry and opioid receptor blockage. Applied Animal Behaviour Science 32, 349-360.

Schnebel, E. M. \& Griswold, J. G. (1983). Agonistic interactions during competition for different resources in captive European wild pigs (Sus scrofa). Applied Animal Ethology 10, 291-300.

Shepherdson, D. J. (1994). The role of environmental enrichment in the captive breeding and reintroduction of endangered species. In Creative Conservation: Interactive Management of Wild and Captive Animals, pp. 167-177 [P. J. S. Olney, G. M. Mace and A. T. C. Feistner, editors]. London: Chapman \& Hall. 
Shepherdson, D. J., Carlstead, K., Mellen, J. D. \& Seidensticker, J. (1993). The influence of food presentation on the behavior of small cats in confined environments. Zoo Biology 12, 203-216.

Stein, B. E., Magalhaes-Castro, B. \& Kruger, L. (1976). Relationship between visual and tactile representations in cat superior colliculus. Journal of Neurophysiology 39, 401-419.

Stolba, A. \& Wood-Gush, D. G. M. (1984). The identification of key features and their incorporation into a housing design for pigs. Annals Recherches de Veterinaire 15, 287-299.

Synder, R. (1977). Putting the wild back into the zoo. International Zoo News 24, 11-18.

Tudge, C. (1991). Last Animals at the Zoo. Oxford: Oxford University Press.

UK Government (1912). Protection of Animals Act $(1911,1912)$. London: H.M. Stationery Office.

Ullrey, D. E. \& Bernard, J. B. (1989). Meat diets for performing exotic cats. Journal of Zoo and Wildlife Medicine 20, 20-25.

Veasey, J. S., Waran, N. K. \& Young, R. J. (1996a). On comparing the behaviour of zoo housed animals with wild conspecifics as a welfare indicator, using the giraffe (Giraffa camelopardalis) as a model. Animal Welfare 5, 139-153.

Veasey, J. S., Waran, N. K. \& Young, R. J. (1996b). On comparing the behaviour of zoo housed animals with wild conspecifics as a welfare indicator. Animal Welfare 5, 13-24.

Williams, B. G., Waran, N. K., Carruthers, J. \& Young, R. J. (1996). The effect of a moving bait on the behaviour of captive cheetahs (Acinonyx jubatus). Animal Welfare 5, 271-281.

Young, R. J. \& Lawrence, A. B. (1996). The effects of high and low rates of food reinforcement on the behaviour of pigs. Applied Animal Behaviour Science 49, 365-374. 